\title{
Deneysel Dalak Yaralanması Yapılan Ratlarda Hemostatik Ajanların Etkinliğinin Karşılaştırılması
}

\section{Comparison of the Effects of Hemostatic Agents in Experimental Splenic Injuries in Rat Models}

\author{
Mustafa ALIMOĞULLARI $^{1}(\mathbb{D})$, Gökhan AKKURT ${ }^{1}(\mathbb{D})$
}

\author{
1 Sağlık Bilimleri Üniversitesi, Keçiören Eğitim ve Araştırma Hastanesi, Genel Cerrahi Kliniği, Ankara, TÜRKiYE \\ 2 Ankara Şehir Hastanesi, Genel Cerrahi Kliniği, Ankara, TÜRKIYE
}

Öz.

Amaç: Travmaya bağlı ölümlerde en sık görülen nedenlerden birisi dalak yaralanmasına bağlı kanamalardır. Çalışmamızda deneysel dalak yaralanması yapılan ratlarda; Ankaferd blood stopper $\left(\mathrm{ABS}^{\circledR}\right.$ ), Oksidize Selüloz (Surgicel ${ }^{\circledR}$ ) ve FloSea ${ }^{\circledR}$ In hemostatik etkinliklerinin karşılaştıııması amaçlandı.

Materyal ve metod: 24 Wistar Albino Ratda grade 2 dalak laserasyonu oluşturuldu; Tüm ratlar; kontrol, ABS, Surgicel ve FloSeal kullanılan olmak üzere, her grupta rastgele 6 rat olacak şekilde 4 gruba ayrıldı. Dalakta grade 2 laserasyon yapıldıktan sonra kontrol grubunda spanç kompresyonu, diğer gruplarda hemostatik ajanlar kullanııld. Gruplar arası; kanama miktarı, süresi ile preoperatif-postoperatif hematokrit ( $\mathrm{Hct}$ ) seviyeleri istatistiksel olarak karşılaştırıld.

Bulgular: Kanama miktarı ve süresi en az FloSeal kullanılan grupta, ardından sırayla ABS, Surgicel ve kontrol grubunda idi. Kanama miktarları sırasılyla; $0.27 \pm 0.04 \mathrm{gr}, 0.38 \pm 0.08 \mathrm{gr}, 0.63 \pm 0.09 \mathrm{gr}$ ve $1.0 \pm 0.2 \mathrm{gr}$ iken kanama süreleri sırasıyla; $65.66 \pm 10.63 \mathrm{~s}$, $70.16 \pm 8.13 \mathrm{~s}, 214.00 \pm 17.98 \mathrm{~s}$ ve $381.83 \pm 59.09 \mathrm{~s}$ idi. Hemostatik ajan kullanılan grupların tümünde kanama miktarı ve süresi kontrol grubuna göre daha az saptandı $(p<0.001)$. FloSeal ve ABS kullanılan gruplarda ise kanama miktarı ve süresi Surgicel'e göre anlamlı olarak azdı (kanama miktarı sırasıyla $p<0.001$ ve $p=0.011$, kanama süresi $p<0.001$ ve $p<0.001$ ). Kanama miktarı ve süresi en az FloSeal grubunda saptanmasına rağmen $A B S$ ile kıyaslandığında bu fark istatistiksel olarak anlamlı değildi (kanama miktarı $p=0.476$, süresi $p=0.842$ )

Sonuç: Çalışmamızda, dalak laserasyonuna bağı kanamalarda kullanılabilen hemostatik ürünlerin, kanamayı durdurmada kontrol grubuna göre çok daha etkin olduğu görüldü. Hemostatik ajanlardan FloSeal başta olmak üzere, ABS'nin de Surgicel'e göre daha etkin bir şekilde hemostazı sağladığı ve kanama miktarını azalttığı da gözlemlendi.

Anahtar Kelimeler: Ankaferd, Dalak, FloSeal, Hemostaz, Oksidize selüloz

Abstract

Background: One of the most common causes of trauma related deaths is hemorrhage due to splenic injury. The aim of the study was to compare the effects of hemostatic activities of Ankaferd blood stopper (ABS $\left.{ }^{\circledR}\right)$, Oxidized Cellulose (Surgicel${ }^{\circledR}$ ) and FloSeal in rats with experimental splenic injuries.

Materials and Methods: In this study we used twenty-four female Wistar Albino rats. Grade 2 spleen laceration was performed on all rats. Rats were randomly divided into four groups each consist of 6 rats, as control, ABS, Surgicel and FloSeal. After performing grade 2 spleen laceration, sponge compression was applied to the control group and hemostatic agents were applied to the other groups. The amount and duration of bleeding and preoperative-postoperative hematocrit (Hct) levels were statistically compared between the groups.

Results: The amount and duration of bleeding was at least in the group using FloSeal, followed by ABS, Surgicel and control group, respectively. The amount of bleeding was; $0.27 \pm 0.04 \mathrm{gr}, 0.38 \pm 0.08 \mathrm{gr}, 0.63 \pm 0.09 \mathrm{gr}$ and $1.0 \pm 0.2 \mathrm{gr}$ respectively. The duration of bleeding was; $65.66 \pm 10.63 \mathrm{~s}, 70.16 \pm 8.13 \mathrm{~s}, 214.00 \pm 17.98 \mathrm{~s}$ and $381.83 \pm 59.09 \mathrm{~s}$ respectively. The amount and duration of bleeding was less in all groups using hemostatic agent compared to the control group $(p<0.001)$. In the groups using FloSeal and ABS, the amount and duration of bleeding were significantly lower than Surgicel group (the amount of bleeding was $p<0.001$ and $p=0.011$, bleeding time $p<0.001$ and $p<0.001$, respectively). Although the amount and duration of bleeding was found at least in the FloSeal group, but this difference was not statistically significant when compared with ABS group (bleeding amount $p=0.476$, duration $p=0.842$ ).

Conclusion: In our study, hemostatic agents that can be used in hemorrhage due to splenic laceration were found much more effective in stopping bleeding than the control group. In particularly, it was observed that FloSeal and ABS provide hemostasis and reduce the amount of bleeding more effectively than oxidized cellulose.

Key words: Ankaferd, FloSeal, Hemostasis, Oxidized cellulose, Spleen.

\section{Sorumlu Yazar I \\ Corresponding Author}

Op.Dr.Mustafa Alimoğulları

Sağlık Bilimleri Üniversitesi, Keçiören Eğitim ve Araştırma Hastanesi, Pınarbaşı Mah. Sanatoryum Cad. Ardahan Sok. No: 25, 06380, Keçiören, Ankara, TÜRKIYE.

Tel: +90 53273375 99;

Fax: +90312 3569000

e-mail: alimogullari49@gmail.com

Geliş tarihi / Received: 26.02.2020

Kabul tarihi / Accepted: 20.05.2020

DOI: 10.35440/hutfd.694637 


\section{Giriş}

Künt abdominal travmalarda, karaciğerden sonra en sık yaralanan organ dalaktır (1). Yaralanma paterni de genellikle laserasyon veya hematom şeklindedir (2). Travmaya bağlı ya da iyatrojenik dalak yaralanmalarında, aşırı kanama nedeniyle splenektomi gerekebilmektedir. Ayrıca dalağın immün sistem modülasyonundaki rolü iyi tanımlanmış olup, pnomoni ve sepsis riskini de azalttığı kanıtlanmıştır (3). Hayati bir organ olmamasına rağmen, önemli fonksiyonları nedeniyle, sadece tamamen rüptüre olduğunda veya hayatı tehdit edecek kanamalarında splenektomi önerilmektedir (4).

Son yıllarda topikal hemostatik ajanlar, splenik kanamaları durdurmada etkin ve güvenilir yöntemler olarak kabul edilmektedir (2). Bu ürünlerin hemostatik mekanizmaları birbirinden farkııdır. Bazıları fibrin oluşumunu artııır iken, bazıları fibrinolizisi inhibe eder, bazıları da kanama yüzeyini kaplayıp sızdırmazlık sağlayarak hemostazı sağlar $(2,5)$. $\mathrm{ABS}^{\circledR}$ bitkilerden üretilen, hemostaz için gerekli olan protein aglütinasyon kaskadını aktive eden bir hemostatik ajandır (6).

Selüloz esasıı ürünler rejenere oksitlenmiş selüloz içerir. Yara boyutuna ve şekline uyacak şekilde kesilebilir ve kolayca manipüle edilebilir. Uygun fiyatı ve yaygınlığı nedeniyle oksidize selülozun en sık bilinen formu Surgicel ${ }^{\mid{ }^{\circledR}} \mathrm{dir}$ (7).

FloSea ${ }^{\circledR}$ ise trombin ve jelatin içeren, sızdırmazlık sağlayan bir hemostatik ajandır (fibrin sealant) (8).

Çalışmamızda ratlarda oluşturduğumuz deneysel grade 2 dalak yaralanmalarında; ABS, Surgicel veya FloSeal kullanarak hemostazı sağlamadaki etkinliklerinin karşılaştırması amaçlanmıştır.

\section{Materyal ve Metod}

Bu çalışma "Ankara Kobay Deney Hayvanları Laboratuvarı (DHL)" nda yürütüldü. Çalışma protokolü "Kobay DHL Etik Kurulu" tarafinca onaylandı (11.10.2019/416).

\section{Hayvan Gruplarl:}

Çalışmamızda toplam 24 adet Wistar Albino cinsi dişi rat (ortalama ağırlık: 280 - 360gr, ortalama yaş: 6 ay) kullanıldı. Ratlar 4 ayrı gruba 6'şar lı olarak rasgele ayrıldı. Bu gruplar; Kontrol, ABS, Surgicel ve FloSeal grubu idi. Hematokrit seviyeleri ratlardan operasyon öncesinde ve postoperatif 24.saatte alınan kanda ölçüldü. Preoperatif kanlar ratların kuyruk veni kanüllenerek, postoperatif 24 .saatte ise intrakardiyak kan alınarak 2 standart Hct tüpü doldurulacak şekilde elde edildi. Tüpler Hct ölçüm cihazında 9.000 rpm'de 5 dakika santrifüj edildi.

\section{Ameliyat Prosedürü:}

24 saat açlığı takiben Ketamin hidroklorür (Ketalar ${ }^{\circledR}$, Pfizer İlaçları Lmt. Şirketi, İstanbul, Türkiye) + $5 \mathrm{mg} / \mathrm{kg}$ Xylazine (Rompun $^{\circledR}$, Bayer, Germany) intraperitoneal olarak verilerek anestezi sağlandı. İşlem sırasında ratların spontan so- lumaları sağlandı. Ratların vücut sıcaklıklarını $37^{\circ} \mathrm{C}$ da tutmak için masa lambası kullanıldı.

Abdomen bölgesi tıraşlandıktan ve temizlendikten sonra $\% 10$ povidon iyodür (Betadin ${ }^{\circledR}$, Kansuk, İstanbul, Türkiye) ile silindi. Xiphoid process'den aşağı doğru $3 \mathrm{~cm}$ orta hat insizyonu ile laparotomi yapıldı. Tüm ratlarda dalak uzun aksı boyunca 15 numara bistüri yardımı ile $10-15 \mathrm{~mm}$ uzunluğunda, $1-1.5 \mathrm{~mm}$ derinliğinde Grade 2 laserasyon yapıldı (Şekil 1). Kanama miktarının tespiti için spançlar her bir denek için operasyon öncesi ve sonrası hassas terazi (Mettler Toledo AB 204-S- USA) ile tartıldı. Tüm ratlarda kanama oluşturulup hızlıca hemostatik ajan tatbik edilmesinden sonra kanama durana kadar geçen süre kronometre yardımı ile kayıt altına alındı.
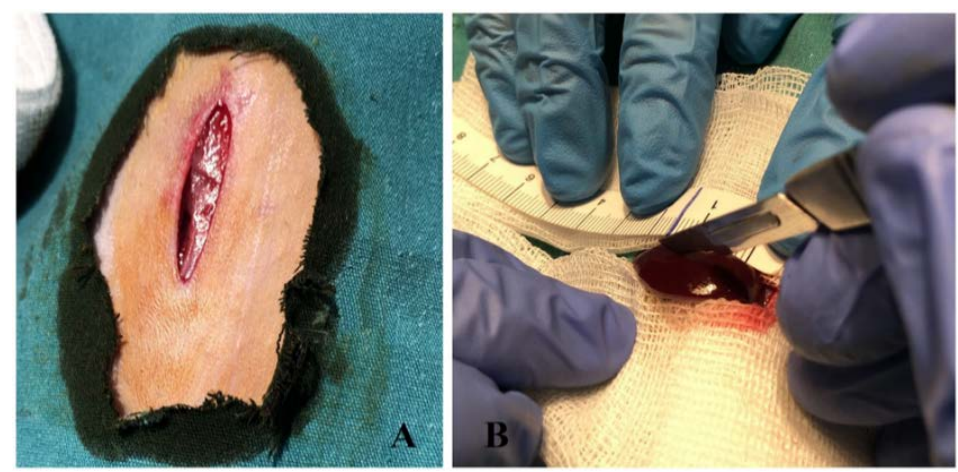

Şekil 1.

A: Xiphoid process'den aşağı doğru yaklaşık $3 \mathrm{~cm}$ 'lik orta hat insizyonu

B: Dalak uzun aksı boyunca oluşturulan Grade 2 laserasyon

Kontrol grubunda; oluşturulan laserasyonu takiben 30 saniye spançlarla kompresyon uygulanıp kanama kontrol edildi, eğer devam ediyorsa hemostaz sağlanana kadar tekrar 30'ar saniye kompresyonlara devam edildi.

Ankaferd grubunda; Ankaferd Blood Stopper ${ }^{\circledR}$ (Trend Teknoloji İlaç AŞ, İstanbul, Türkiye) dalak laserasyonunu takiben $3 \mathrm{ml}$ enjektör yardımı ile kanama alanı üzerine sıkılıp beklenildi (Şekil 2).
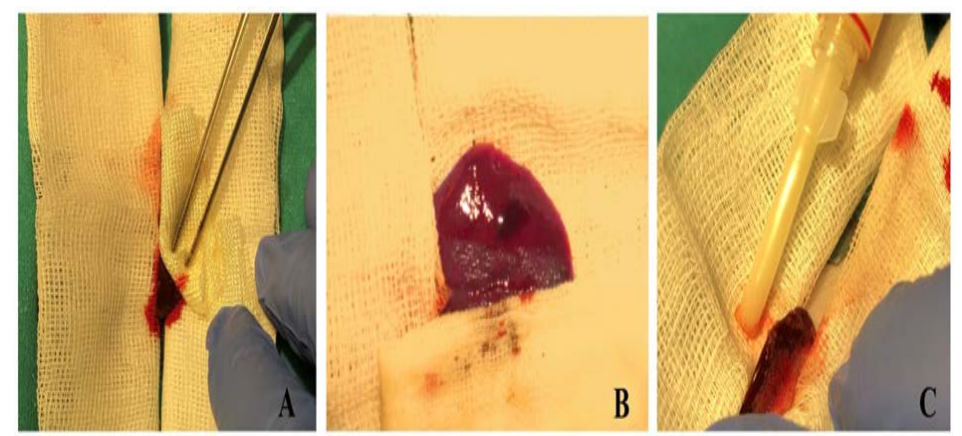

Şekil 2.

A: Surgicel Uygulaması

B: Ankaferd Uygulaması

C: FloSeal Uygulaması 
Surgicel grubunda; çift katmanlı bir Surgice ${ }^{\circledR}$ parçası (Ethicon Inc.,Johnson \& Johnson Co., Somerville, New Jersey, ABD) dalaktaki kanama alanına insizyonun hemen ardından yerleştirilerek kanamayı durdurması sağlandı (Şekil 2).

FloSeal grubunda; ürün prospektüsünde açıklandığı üzere hazırlanan FloSeal ${ }^{\circledR}$ (Baxter; Münih, Almanya) kanama alanına yaklaşık $1 \mathrm{~mL}$ sürülerek, ancak prospektüsünde açıklanandan farklı olarak spanç kompresyonu yapılmadan beklenerek kanamayı durdurması sağlandı (Şekil 2). Kanamalar durduktan sonra batın kapatılmadan ve kompresyon uygulanmadan on dakika daha geç kanama olasıllğına karşı beklendi. Kanama süresi cerrahi alanda kanama durduktan sonra 10 dakika daha kanama olmaması durumunda kayıt altına alındı. Ardından orta hat $3 / 0$ vicryl yardımı ile kapatılarak ameliyat sonlandırılı. Postoperatif 24 saat sonra intrakardiak 4-5 ml kan alınarak ratlar sakrifiye edildi ve alınan kanlardan Hct değerleri çalışılarak kayıt altına alındı.

Istatiksel Analiz:

Analizler SPSS 23.0 (SPSS Inc., Chicago, Illinois, USA) kullanılarak yapıldı. Gruplar arası ortalama değer farkları varyans analizi (One-way ANOVA) ile gerçekleştirildi. Tanımlayıcı analizler ile değişkenlerin ortalama ve standart deviasyonları belirlendi. Grupların dağılımlarının değerlendirilmesinde Shapiro Wilk-W testi kullanıldı. Grupların dağılımı değerlendirildiğinde kanama süresi için dağılım homojen olmadığından grupların kendi aralarındaki farkların değerlendirimesi için Games-Howell post-hoc testi kullanıldı. Diğer parametrelerde dağılım normal olduğundan, grupların kendi aralarındaki farkların değerlendirilmesi için Tukey post-hoc testi kullanıldı. İstatistiksel anlamlılık için $p$ değeri $<0.05$ olarak kabul edildi.

\section{Bulgular}

Çalışmada hiçbir ratta geç dönem kanama ve mortalite görülmedi. Ayrıca operasyon sonrası kanama başta olmak üzere herhangi bir komplikasyonla karşılaşılmadı.

Tablo 1. Kanama miktarının karşılaşıııılması

\begin{tabular}{|c|c|c|c|c|}
\hline & Grup & Ortalama & I Std. Sapma & $p$ \\
\hline \multirow{4}{*}{$\begin{array}{l}\text { Kanama miktarı } \\
\text { (gram) }\end{array}$} & Kontrol & 1,01 & 0,208 & \multirow{4}{*}{$<0.001$} \\
\hline & Surgicel & 0,63 & 0,095 & \\
\hline & ABS & 0,38 & 0,081 & \\
\hline & FloSeal & 0,27 & 0,049 & \\
\hline
\end{tabular}

ABS: Ankaferd Blood Stopper

\section{Kanama Miktarlarl:}

Operasyon boyunca kanama miktarları; kontrol grubunda $1.0 \pm 0.2 \mathrm{gr}$, Surgicel grubunda $0.63 \pm 0.09 \mathrm{gr}$, ABS grubunda $0.38 \pm 0.08 \mathrm{gr}$ ve en az FloSeal grubunda $0.27 \pm$ 0.04 gr olarak saptandı. (Tablo 1). Alt grupların analizinde; hemostatik ajan kullanılan tüm gruplarda kanama miktarı kontrol grubuna göre daha az olarak saptandı $(p<0.001)$. Ayrıca FloSeal ve ABS gruplarında kanama miktarı Surgicel'e göre anlamlı olarak azdı (sırasıyla $p<0.001$ ve $p=0.011)$. FloSeal ve ABS grupları arasında ise kanama miktarları arasında istatistiksel olarak anlamlı fark bulunmadı ( $p=0.476$ ) (Tablo 2).

Tablo 2. Kanama miktarı açısından gruplar arasındaki farklılıkları gösteren "p değerleri"

\begin{tabular}{l|l|l}
\hline Grup & \multicolumn{2}{l}{ Kanama Miktarı } \\
\hline & Grup & $\mathbf{p}$ \\
\hline Kontrol & Surgicel & $<0.001$ \\
& ABS & $<0.001$ \\
& FloSeal & $<0.001$ \\
\hline Surgicel & Kontrol & $<0.001$ \\
& ABS & 0.011 \\
& FloSeal & $<0.001$ \\
\hline ABS & Kontrol & $<0.001$ \\
& Surgicel & 0.011 \\
& FloSeal & 0.476 \\
\hline FloSeal & Kontrol & $<0.001$ \\
& Surgicel & $<0.001$ \\
& ABS & 0.476 \\
\hline
\end{tabular}

Tablo 3. Kanama süresinin karşılaştııılması

\begin{tabular}{l|l|l|l|l}
\hline & Grup & Ortalama & $\mathbf{\pm}$ Std. Sapma & \multirow{2}{*}{$\mathbf{p}$} \\
\hline \multirow{2}{*}{$\begin{array}{l}\text { Kanama Süresi } \\
\text { (saniye) }\end{array}$} & Kontrol & 381,83 & 59,091 & \multirow{2}{*}{$<0.001$} \\
\cline { 2 - 4 } & Surgicel & 214,00 & 17,988 & \\
\cline { 2 - 4 } & ABS & 70,16 & 8,134 & \\
\cline { 2 - 4 } & FloSeal & 65,66 & 10,633 & \\
\hline
\end{tabular}

ABS: Ankaferd Blood Stopper

\section{Kanama Süreleri:}

En kısa kanama süresi FloSeal kullanılan grupta $65.66 \pm$ $10.63 \mathrm{~s}$ olarak saptandı. (Tablo 3). Ardından sırasıyla; $70.16 \pm 8.13$ s ile ABS grubu, $214.00 \pm 17.98$ s ile Surgicel grubu ve en uzun süre olarak $381.83 \pm 59.09$ s ile kontrol grubu olduğu saptandı. Hemostatik ajan kullanılan grupların üçünde de kontrol grubuna göre kanama süresi anlamlı olarak daha kısaydı $(p<0.001)$. Surgicel grubunda kanama süresi FloSeal ve $A B S$ ajanlarına göre anlamlı olarak daha uzun $(p<0.001)$ iken FloSeal ve ABS grubu arası kanama süresi farkı istatistiksel olarak anlamlı değildi $(p=0.842)$ (Tablo 4).

\section{Hematokrit Değerleri:}

Preoperatif Hct değerleri arasında farklılık yoktu $(p=0.784)$. Preoperatif ve postoperatif 24.saatte alınan kan değerlerindeki Hct farkına bakıldığında ise kontrol grubunda 8.03 \pm 0.89 , Surgicel grubunda $5.12 \pm 0.54$, ABS grubunda 4.20 \pm 0.45 ve FloSeal grubunda $3.89 \pm 0.18$ olarak saptandı. Hct değişikliği ve postoperatif Hct değerleri değerlendirildiğinde hemostatik ajan kullanılan gruplarda kontrol grubuna göre anlamlı fark görüldü $(p<0.001)$ (Tablo 5). FloSeal ve ABS gruplarındaki Hct değişim farkı Surgicel'e göre kıyaslandığında; $A B S$ de istatistiksel anlamlı değilken FloSeal de anlamlı olarak azdı (sırasıyla $p=0.054$ ve $p=0.008$ ). FloSeal ve ABS grupları arasındaki Hct değişim farkları arasında ise istatistiksel olarak anlamlı fark bulunmadı $(p=0.804)$. 
Tablo 4. Kanama süresi açısından gruplar arasındaki farklılıkları gösteren "p değerleri"

\begin{tabular}{l|l|l}
\hline & Grup & $\mathbf{p}$ \\
\hline Kontrol & Surgicel & 0.002 \\
& ABS & $<0.001$ \\
& FloSeal & $<0.001$ \\
\hline Surgicel & Kontrol & 0.002 \\
& ABS & $<0.001$ \\
& FloSeal & $<0.001$ \\
\hline ABS & Kontrol & $<0.001$ \\
& Surgicel & $<0.001$ \\
& FloSeal & 0.842 \\
\hline FloSeal & Kontrol & $<0.001$ \\
& Surgicel & $<0.001$ \\
& ABS & 0.842 \\
\hline ABS:Ankafed
\end{tabular}

ABS: Ankaferd Blood Stopper

Tablo 5. Hematokrit düzeylerinin karşılaştıııması

\begin{tabular}{|c|c|c|c|c|c|}
\hline & arametre & Grup & Ortalama & \pm Std. & $p$ \\
\hline \multirow{12}{*}{ 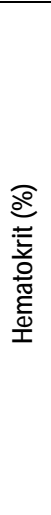 } & \multirow{4}{*}{$\begin{array}{l}\text { Preoperatif } \\
\text { Hct }\end{array}$} & Kontrol & 54,96 & 0,551 & \multirow{4}{*}{0.784} \\
\hline & & Surgicel & 55,13 & 0,954 & \\
\hline & & ABS & 55,49 & 1,258 & \\
\hline & & FloSeal & 55,47 & 1,304 & \\
\hline & \multirow{4}{*}{$\begin{array}{l}\text { Postoperatif } \\
\text { Hct }\end{array}$} & Kontrol & 46,93 & 0,753 & \multirow{4}{*}{$<0.001$} \\
\hline & & Surgicel & 50,01 & 1,092 & \\
\hline & & $\overline{A B S}$ & 51,28 & 1,444 & \\
\hline & & FloSeal & 51,57 & 1,452 & \\
\hline & \multirow{4}{*}{$\begin{array}{l}\text { Hct } \\
\text { değişimi } \\
\text { (Preop - } \\
\text { Postop) }\end{array}$} & Kontrol & 8,03 & 0,897 & \multirow{4}{*}{$<0.001$} \\
\hline & & Surgicel & 5,12 & 0,544 & \\
\hline & & ABS & 4,20 & 0,451 & \\
\hline & & FloSeal & 3,89 & 0,187 & \\
\hline
\end{tabular}

Hct: Hematokrit, ABS: Ankaferd Blood Stopper

\section{Tartışma}

Splenik cerrahiler, dalağın yüksek vasküler yapısı dolayısıyla, parankimal hemostazı sağlamada zorluklar yaşanması nedeniyle zordur (4). Künt batın travmalarında savunmasız olması nedeniyle, karaciğerden sonra en sık yaralanan organ dalaktır $(1,9)$. Splenektomi yapılan hastalarda, normal bireylere göre ciddi enfeksiyonlar ve sepsise bağlı ölümler istatistiksel olarak daha fazla görülmektedir (10). Bu nedenle dalak olabildiğince korunmalı ve işlevselliğinin devamı sağlanmalıdır.

Cerrahi tekniklerdeki ilerlemeler ve geliştirilen hemostatik ajanlar sayesinde travma veya iyatrojenik gelişen dalak travmalarında, morbidite ve mortalite yıllar içinde azalmıştır $(4,9)$. Splenik cerrahide kan kaybı miktarı birçok faktöre bağlıdır. Bunlar; sistemik koagülasyon, santral venöz basınç, lokal hemodinamikler, altta yatan hastalık, cerrahın deneyimi, ameliyat tipi ve zorluğu gibi sıralanabilir (4).

Son yıllarda etkinlikleri nedeniyle topikal hemostatik ajanların kullanımı artmıştır. Topikal hemostatik ajanların çoğunda temel etki mekanizmasi; trombositlerle temas ettikten sonra aktive olmalarını sağlayarak, doğal hemostatik mediyatörlerin sekresyonlarını hızlandırmaktır. Bazı maddelerde yardımcı etki mekanizmaları da mevcuttur. Örnek olarak fibrin preparatlarda yapıştırıcı, selüloz ve sığır kollajeninde ise tıkaç oluşturucu etkiler vardır (11).

Çalışmamızda etki mekanizmaları farkı olup, ülkemizde kullanımı sık olan ABS, Surgicel ve FloSeal'ın hemostaz sağlamadaki etkinliklerini karşılaştırmak amaçlandı.

Surgicel bir oksidize rejenere selülozdur. Konulduğu yerde su çekerek şişer ve selülozik aside dönüşerek yapay bir pıntı oluşturur (11). Ankaferd Blood Stopper; 2 ml'lik ampülde, hematolojik ve vasküler etkileri olan beş bitkisel ekstrenin (Urtica dioica, Vitis vinifera, Glycrrhiza glabra, Alpinia officinarum ve Thymus vulgaris) belirli oranlarda standardize edilmiş karışımıdır. Hemostatik etkisini klasik koagülasyon kaskadından bağımsız olarak, protein ağı ortamında fizyolojik eritrosit agregasyonu yaparak gösterir (12). FloSeal hemostatik matriks; sığır kökenli bir jelatin bazlı matrisin ve insan türevi trombin bileşenlerinin bir kombinasyonudur. Kanla temas ettiğinde jelatin partiküller şişer kanamayı tampon şeklinde durdurur ve trombinler de pıitı oluşumunu hızlandıır (13). FloSeal prospektüsünde kanama alanına yeterli miktarda sürüldükten sonra üzerine nemli gazlı bez ile 5 dakika boyunca hafif basınç uygulayarak sabitlenmesi gerektiği belirtilmektedir. Ancak kendi klinik tecrübelerimizde, laparoskopik cerrahilerde oluşan kanamalarda FloSeal kullandığımızda üzerine basınç uygulamaksızın kanamayı durdurmadaki hızı ve etkinliği tarafımızca gözlemlenmiştir. Bu nedenle biz çalışmamızda FloSeal'ı kanama yüzeyine sıktıktan sonra üzerine nemli spançla basınç uygulamadan, kanamayı kendiliğinden durdurmasını bekledik. Literatüre baktığımızda FloSeal ile ilgili yapılan deneysel çalışmalarda ürünün bu şekilde uygulandığı bir çalışma göremedik.

Laparoskopik ameliyatlardaki kanamaların kontrolü teknik olarak açık ameliyatara göre daha zordur. Bu nedenle laparoskopik ameliyatlardaki kanamalarda topikal hemostatik ajanların rolü daha da önem kazanmaktadır (14). Ancak bu ürünlerin laparoskopik kullanımında belli handikaplar yaşanabilmektedir. FloSeal'ın laparoskopik kullanımına yönelik aparatları ile uygulanması kolay iken, ABS'nin laparoskopik uygulama aparatı bulunmamaktadır. Surgicel ise laparoskopik enstrümanlar yardımı ile trokardan batın içine alınıp uygulanabilmektedir. Vecchio ve ark. yaptığı çalışmada laparoskopik cerrahilerde geniş alanı ilgilendiren yoğun kanamalarda FloSeal gibi fibrin sealantlarının kullanımını önermektedir (14).

Biz çalışmamızda ratlarda dalakta oluşturduğumuz grade 2 laserasyona bağlı kanamayı durdurmada; topikal hemostatik ajanlar olan ABS, Surgicel ve FloSeal'ı kullanarak; kanama süresi, kanama miktarı ve preoperatif - postoperatif Hct miktarlarını kıyaslayarak hemostatik etkinliklerini karşılaştırmayı amaçladık. Ayrıca hemostatik ajan kullanmadığımız sadece kompresyon ile kanamayı durdurduğumuz bir kontrol grubu ekledik. Literatüre baktığımızda da bu üç hemostatik ajanın dalak kanamaları üzerine etkinliğinin karşılaştırıldığı bir çalışma göremedik. 
Karakaya ve ark. yaptığı çalışmada (12), ABS ile Surgicel'in ratlarda karaciğer yaralanma modeli üzerinde etkinlikleri karşılaştıılımış. ABS'nin hemostazı sağlamada Surgicel kadar etkin olduğu saptanmış. Satar ve ark. yaptığı çalışmada ise (15); ratlarda karaciğer yaralanma modelinde ABS, Surgicel ve kontrol grubu karşılaştırılmış, kanama süreleri en kIsa ABS sonra Surgicel en uzun da kontrol grubunda saptanmış. Biz de çalışmamızda Satar ve ark. yaptığı çalışma ile uyumlu olarak; kanama süresinin ABS grubunda, Surgicel grubuna göre daha kısa olduğunu ve ayrıca bu her iki gruptaki sürelerin de kontrol grubundan daha kısa olduğunu saptadık. Çalışmamızda FloSeal kullanılan grupta ise kanama süresinin hepsinden daha kısa olduğunu saptadık. Kanama sürelerinde FloSeal ile ABS grubu arasındaki fark istatistiksel anlamlı değilken, bu iki grup ile Surgicel grubu ve kontrol grubu aralarındaki fark ise istatistiksel olarak anlamlı idi. Fonouni ve arkadaşlarının yaptığı çalışmada (16); dört ayrı topikal sealant (TachoSil ${ }^{\circledR}$, Tissucol Duo ${ }^{\circledR}$, Coseal $^{\circledR}$ ve FloSea $\left.{ }^{\circledR}\right)$ kullanılarak hemostazdaki üstünlükleri kontrol grubu ile kıyaslanmış. Kanama süresi, miktarı ve Hct değerleri kıyaslandığında hemostazda en etkin ürün TachoSil saptanmış. Ardından sırası ile Coseal, Tissucol Duo ve FloSeal olduğu ve tüm sealantların kontrol grubuna göre hemostazda etkin oldukları gözlenmiştir.

Dorterler ve ark. yaptığı çalışmada (17), deneysel karaciğer yaralanmalarında intraoperatif kanama miktarl; $A B S$ kullanılan grupta en az iken ardından sırasıyla Surgicel, Sorbalgon ve kontrol grubu olarak sıralanmış. Davidson ve ark. yaptığı çalışmada ise (18), deneysel hepatektomide Surgicel, fibrin doku yapıştırıcısı (Vivostat ${ }^{\circledR}$ ) ve kontrol grubunda kanama miktarları karşılaştııımış ve en az kanama miktarı Vivostat kullanılan grupta, sonra Surgicel, en fazla miktarda da kontrol grubunda olduğu görülmüş ve istatistiksel olarak anlamlı saptanmış. Biz de çalışmamızda kanama miktarını en düşük FloSeal kullanılan grupta ardından ABS grubu ve sonrasında Surgicel, son sırada da kontrol grubunda gözlemledik. Kanama miktarlarında FloSeal ile ABS grubu arasındaki fark istatistiksel anlamlı değilken, bu iki grup ile Surgicel grubu ve kontrol grubu aralarındaki fark ise istatistiksel olarak anlamlı idi.

Satar ve ark. yaptığı çalışmada (15), preoperatif - postoperatif Hct değişimlerinde herhangi bir istatistiksel farklılık görülmemiş. Dorterler ve ark. yaptığı çalışmada ise (17) topikal hemostatik ajan kullanılan gruplar arasında Hct farkı saptanmamışken, bu gruplar ile kontrol grubu arasında istatistiksel anlamlı fark saptanmış. Bizim çalışmamızda preoperatif - postoperatif Hct değişimi en az FloSeal kullanılan grupta ardından ABS grubu, sonrasında Surgicel, son sIrada da kontrol grubunda idi. Hemostatik ajan kullanılan grupların tümünde kontrol grubuna göre Hct değişiminde istatistiksel anlamlı farklıık saptandı. Ayrıca Surgicel kullanılan grupta FloSeal grubuna göre anlamlı derecede fazla idi. FloSeal ile ABS grubu arasında ve ABS ile Surgicel grubu arasında ise anlamlı fark yoktu.

Rejenerasyon, doku inflamasyonu ve nekroz çalışmamızın odak noktası değildi, bu nedenle histolojik analiz için biyopsi örnekleri alınmadı.

Hemostatik ajan seçiminde önemli olan faktörler; ucuz olması, kullanımının kolay olması ve hemostazı hızı ı ve etkin bir şekilde sağlayabilmesidir. Kanamanın hızlı ve etkin bir şekilde kontrol edilmesi de postoperatif komplikasyonları azaltır, ayrıca transfüzyon intiyacını ve buna bağlı komplikasyonları azaltır. Bunlara ek olarak ameliyat süresini ve hastanede yatış süresini kısaltarak maliyetleri de azaltır (19). ABS ve Surgicel'in kullanımı kolay iken FloSeal kullanımı için bir hazırlık gerektirdiğinden nispeten daha zordur. Kullandığımız hemostatik ajanların fiyatlarını kıyasladığımızda en ucuz ürün Surgicel sonra ABS iken, en pahalısı da FloSeal'dir. Yüksek maliyeti FloSeal'ın kullanımında en önemli dezavantajıdır.

Çalışmamızdaki en önemli kısıtlılık örnek gruplarının az olmasıdır. Daha fazla sayıda rat içeren geniş serilerin daha iyi sonuçlar verebileceği düşüncesindeyiz.

Sonuç olarak çalışmamızda ratlarda oluşturulan grade 2 deneysel dalak yaralanmalarında hemostazı sağlamada kullanılan üç hemostatik ajanın (FloSeal, ABS, Surgicel) da kompresyon yapılan kontrol grubuna göre kanama miktarını azalttığı, kanama süresini kısalttığı belirlenerek, daha etkili bir şekilde kanamayı durdurduğu gösterilmiştir. Bu üç hemostatik ajan arasında en az etkini Surgicel iken, istatistiksel olarak anlamlı olmasa da en etkini FloSeal olduğu gösterilmiştir.

\section{Açıklamalar}

Çalışmayı maddi olarak destekleyen kişi/kuruluş olmadığını ve yazarların herhangi bir çıkar dayalı ilişkisi olmadığını beyan ederiz.

Etik onam: Bu çalışma "Ankara Kobay Deney Hayvanları Laboratuvarı (DHL)" nda yürütüldü. Çalışma protokolü "Kobay DHL Etik Kurulu" tarafınca onaylandı (11.10.2019/416).

\section{Kaynaklar}

1. Soto JA, Anderson SW. Multidetector CT of blunt abdominal trauma. Radiology 2012; 265(3):678-93.

2. Boscak $A$, Shanmuganathan K. Splenic trauma: what is new? Radiol Clin N Am. 2012;50(1):105-22.

3. Modi P, Rahamim J. Fibrin sealant treatment of splenic injuries during oesophagectomy. Eur J Cardiothorac Surg. 2005;28(1):167-8.

4. Hildebrand P, Roblick UJ, Schloricke E, Czymek R, Bruch HP, Burk C. The role of organ preservation in the surgical therapy of traumatic spleen injury. Acta Chir lugosl. 2011;58(4):21-5.

5. Kraus TW, Mehrabi A, Schemmer P, Kashfi A, Berberat P, Buchler MW. Scientific evidence for application of topical hemostats, tissue glues, and sealants in hepatobiliary surgery. J Am Coll Surg 2005;200(3):418-27.

6. Beyazit Y, Kurt M, Kekilli M, Goker H, Haznedaroglu IC. Evaluation of hemostatic effects of Ankaferd as an alternative medicine. Altern Med Rev. 2010;15(4):329-36.

7. Takacs I, Wegmann J, Horvath S, Ferencz A, Ferencz S, Javor S, et al. Efficacy of different hemostatic devices for severe liver bleeding: a 
randomized controlled animal study. Surg Innov. 2010;17(4):346-52.

8. Barnard J, Millner R. A review of topical hemostatic agents for use in cardiac surgery. Ann Thorac Surg. 2009;88(4):1377-83.

9. Richardson JD. Changes in the management of injuries to the liver and spleen. J Am Coll Surg. 2005;200(5):648-69.

10. Leonard AS, Giebink GS, Baesl TJ, Krivit W. The overwhelming postsplenectomy sepsis problem. World J Surg. 1980;4(4):423-32.

11. Kohno $\mathrm{H}$, Nagasue $\mathrm{N}$, Chang $Y C$, Taniura $H$, Yamanoi A, Nakamura T. Comparison of topical hemostatic agents in elective hepatic resection: a clinical prospective randomized trial. World J Surg. 1992;16(5):966-9.

12. Karakaya K, Ucan HB, Tascilar O, Emre AU, Cakmak GK, Irkorucu $\mathrm{O}$, et al. Evaluation of a new hemostatic agent Ankaferd Blood Stopper in experimental liver laceration. J Invest Surg. 2009;22(3):201-6.

13. Moore K.L, Dalley A.F. Kliniğe yönelik anatomi. 3. Baskı, Nobel Tıp Kitabevleri, İstanbul. 2007:263-71.

14. Vecchio R, Catalano R, Basile F, Spataro C, Caputo M, Intagliata E. Topical hemostasis in laparoscopic surgery. G.Chir. 2016;37(6):266-70 15. Satar N, Akkoc A, Oktay A, Topal A, Inan K. Evaluation of the hemostatic and histopathological effects of Ankaferd Blood Stopper in experimental liver injury in rats. Blood Coagul Fibrinolysis. 2013;24(5):518-24.

16. Fonouni $H$, Kashfi A, Majlesara A, Stahlheber O, Konstantinidis L, Gharabaghi N, et al. Hemostatic efficiency of modern topical sealants: Comparative evaluation after liver resection and splenic laceration in a swine model. J Biomed Mater Res B Appl Biomater. 2018;106(3):130716

17. Dorterler ME, Ayangil HR, Turan C, Deniz K. Comparison of the hemostatic effects of oxidized cellulose and calcium alginate in an experimental animal model of hepatic parenchymal bleeding. Int J Crit IIIn Inj Sci. 2016;6(4):167-71

18. Davidson BR, Burnett S, Javed MS, Seifalian A, Moore D, Doctor N. Experimental study of a novel fibrin sealant for achieving haemostasis following partial hepatectomy. Br J Surg. 2000;87(6):790-5.

19. Mankad PS, Codispoti M. The role of fibrin sealants in hemostasis Am J Surg. 2001;182(Suppl 2):21-8. 